\title{
Sources of stress, psychological distress and burnout in psychiatrists
}

\section{Comparison of junior doctors, senior registrars and consultants}

\author{
Elspeth Guthrie, Teresa Tattan, Edwina Williams, Dawn Black and \\ Himant Bacliocotti
}

\begin{abstract}
Alms To assess the degree of psychological morbidity and burnout in 138 psychiatrists in three Manchester teaching hospitals.

Reeults The results for senior house officers (SHOS), registrars, senior registrars and consultants were compared. The overall response rate was $76.8 \%$. There was no significant difference in psychological morbidity between the three training grades, but SHOS and registrars reported significantly higher levels of burnout than elther senior registrars or consultants. Dealing with violent patients was stressful for all psychiatrists, no matter what the grade.

Clinical implications Factors related to job stress in psychiatry need to be addressed. In particular, the provision of safer working environments needs to be considered for psychiatrists at all levels of training.
\end{abstract}

Recent studies have reported high levels of psychological distress in both junior hospital doctors (Firth-Cozens, 1987), and consultants (Ramirez et al, 1996; Deary et al, 1996a). Out of all the medical specialities, psychiatrists have the most intense form of interpersonal contact with patients, dealing on a regular basis with extremely distressed or disturbed individuals. Although, consultant psychiatrists work fewer hours on average than consultant physicians or surgeons, they report more emotional exhaustion and more severe depression as a result of workload (Deary et al, 1996b) than either physicians or surgeons. This difference may be due to the particular nature of the work that consultant psychiatrists undertake, or due to particular personality characteristics of psychiatrists which make them vulnerable to job stress. Psychiatrists have higher neuroticism scores than physicians or surgeons (Deary et al. 1996b), and medical students expressing a preference for psychiatry have a higher score on 'complexity traits' (Walton, 1969) and a more abstract approach to problem-solving (Ney et al, 1990) than other students.

Worryingly, psychiatrists have higher rates of suicide than other specialities, although the studies in this area are rather old (Rich \& Pitts, 1980).

There is little work which has directly compared the prevalence of psychological morbidity in psychiatrists at different stages of their training, or studied the different kinds of stressors faced by psychiatrists as they progress up the career ladder.

The aim of this study was to compare: the degree of psychological distress, the degree of burnout and the kind of stressors reported by psychiatrists at different stages of training in three hospitals in the Manchester area.

\section{The study}

All senior house officers, registrars, senior registrars and consultants at three large hospitals in Manchester were asked to complete a confidential self-report questionnaire. The following assessments were employed.

\section{General Health Questionnaire (GHQ-12;} Goldberg \& Williams, 1988)

This is a widely used self-report measure which was designed as a screening device for estimating minor psychiatric disorder in the general population. It has been found useful for assessing stress in occupational settings and as an estimate of psychiatric caseness. The usual threshold score is either $1 / 2$ or $2 / 3$. In the present study, the GHQ method of scoring was 
used and a high threshold score of $3 / 4$ was taken as an indication of probable caseness.

\section{Maslach Burnout Inventory (Maslach \& Jackson, 1981)}

This 22-item self-report questionnaire is a well recognised and widely used measure of burnout in relation to occupational stress. It has three sub-scales: personal accomplishment (feelings of competence and achievement) which is measured by eight items; depersonalisation (feeling detached and uninvolved with patients) which is measured by nine items; and emotional energy (feeling emotionally drained by work) measured by five items. Respondents are asked to rate each item according to frequency on a seven-point scale from 'never' to 'every day'. The total score for each sub-scale is categorised 'low', 'average', or 'high' according to predetermined cut-off scores based on normative data from a sample of American health professionals. A high degree of burnout is indicated by high scores on the emotional energy and depersonalisation subscales and low scores on the personal accomplishment sub-scale.

\section{Stress Incident Record (Keenan \& Newton, 1985)}

This measure examines acute stressors and has been used in previous studies of medical students and hospital doctors (Firth-Cozens, 1987). It requires respondents to "describe briefly a real event which has occurred in the past month and which has been stressful to you (Note: a stressful event is one which has aroused your feelings in some negative way)". The respondents are then asked to describe feelings invoked by the incident by rating a list of 15 feelings on a five-point scale from 'not at all' to 'extremely'. The incidents described by the psychiatrists were subjected to a content analysis by grouping together similar descriptions. This was carried out by two independent raters. (F. W. and T. T.).

\section{Additional ratings of stressors}

The psychiatrists were also asked to rate $\mathbf{3 0}$ work-related items on a four-point scale $(0=$ not stressful to $3=$ extremely stressful). The scale was adapted from a scale used by Firth-Cozens to measure stress in junior doctors. Additional items, specifically relevant to psychiatry were added. These included: "dealing with violent patients". "dealing with angry patients". "dealing with sexual problems". The scores for the different grades of psychiatrist were compared for each item. In addition, the mean score from the scale was used as an indicator of overall stress.

The data were analysed using the Statistical Package for the Social Sciences (SPSS). Nonparametric statistics were employed. Data from the three groups were compared using the Kruskal-Wallis one-way analysis of variance. The proportion of psychiatrists who rated different items on the 'work-related scale' as moderately or very stressful were compared for cases and non-cases on the GHQ-12 using the $\chi^{2}$ test. Differences in gender were compared using the Mann-Whitney $U$-test.

\section{Findings}

One hundred and thirty-eight doctors were sent questionnaires of whom $106(76.8 \%)$ responded (51.1\% were male, $n=54)$. The response rates for each grade were as follows: SHOs/registrars 31/ $46(67.4 \%)$, senior registrars $33 / 42(78.6 \%)$ and consultants $42 / 50$ (84\%). The gender distribution for the different grades was as follows: consultants (males) $59.6 \%$, senior registrars

Table 1. GHQ scores and sub-scales of the Maslach Burnout Inventory

\begin{tabular}{|c|c|c|c|c|c|c|}
\hline & $\begin{array}{l}\text { SHOI } \\
\text { registrars } \\
(n=31)\end{array}$ & $\begin{array}{l}\text { Senior } \\
\text { registrar } \\
(n=33)\end{array}$ & $\begin{array}{l}\text { Consultant } \\
(n=42)\end{array}$ & $\chi^{2}$ & d.f. & $\mathbf{P}$ \\
\hline GHQ (high scores (>4)) (\%) & $11(36.6)$ & $6(18.2)$ & $10(23.8)$ & 3.1 & 2 & $P=0.21$ \\
\hline $\begin{array}{l}\text { Burnout (\%) } \\
\text { High emotional } \\
\text { exhaustion scores }\end{array}$ & $17(54.8)$ & $11(33.3)$ & $11(26.2)$ & 8.9 & 2 & $P=0.01$ \\
\hline $\begin{array}{l}\text { Low personal } \\
\text { accomplishment score }\end{array}$ & $14(45.2)$ & $15(45.4)$ & $14(33.3)$ & 1.5 & 2 & $P=0.45$ \\
\hline High depersonalisation & $15(48.4)$ & $11(33.3)$ & $6(14.3)$ & 11.5 & 2 & $P<0.01$ \\
\hline $\begin{array}{l}\text { Stress (\%) } \\
\text { Total stress score }\end{array}$ & $41(29-50)$ & $30(21-42)$ & $28(19-34)$ & 10.58 & & $P<0.01$ \\
\hline
\end{tabular}

1. Kruskal-Wallis test, median (interquartile range), Kruskal-Wallis $\chi^{2}$. 
(males) $60.7 \%$, registrars/SHOs (males) $35.5 \%$. The median GHQ score for the whole sample was 1.0 (range 0-4), 27 (31.4\%) doctors reported scoring above threshold. There was no significant difference in GHQ scores by gender. The median and interquartile range scores for males and females were as follows: males $1.0(0.0-4.0)$, females $1.0(0.0-4.2)(Z-0.23, P=0.81)$. There was no significant difference in $\mathrm{GHQ}-12$ scores across the different grades (Table 1), although SHOs/registrars had higher scores than the other two groups.

On the Maslach Burnout Inventory 42 doctors $(39.6 \%)$ out of the whole sample were high scorers on the emotional exhaustion sub-scale. 33 (31.1\%) were high scorers on the depersonalisation sub-scale and $42(39.6 \%)$ were low scorers on the personal accomplishment subscale. There was, however, a significant difference between the three psychiatric grades on two of the sub-scales of the Maslach Burnout Inventory (Table 1). A far greater proportion of SHOs and registrars reported feelings of severe emotional exhaustion and depersonalisation than either senior registrars or consultants. All three grades reported similar levels of satisfaction and personal accomplishment from their work.

Eighty-three (78.3\%) of the sample reported a stressful incident. The main kinds of acute incident, according to grade, are shown in Table 2. Examples of each kind of stressor are also included in the table. The four most frequently cited stressors, by the group as a whole, were: personal problems, problems involving patients (such as suicide or violence), career threat (such as a formal complaint) and administrative problems (such as lack of beds). There was, however, a marked difference between the kinds of stressors that were most frequently cited according to grade.

Administrative difficulties and career threats were the most frequently cited stressors by consultants. The emphasis upon community care and the closure of large numbers of psychiatric beds without sufficient community resources was frequently commented upon. Consultants described spending hours trying to arrange beds for patients in hospitals over 100 miles away from Manchester. They also described the stress of carrying medical responsibility for suicidal and homicidal patients without any power to influence service delivery.

For SHOs and registrars, dealing with patients and managing personal problems, were the most common stressors. In particular, junior psychiatrists commented upon the difficulties posed by personal life events influencing the ability to deal with patients' emotional problems. Examples of this included the deaths of relatives and in one case the suicide of a psychiatrist's close relative.

Registrars scored significantly higher on the overall stress score from the 30 -item stress questionnaire (Table 1). Table 3 shows the items where there was a difference in scoring across the grades and it also shows other items which were rated highly by all three grades. The

Table 2. Types of stressor identified by the stress incident record

\begin{tabular}{|c|c|c|c|c|c|c|}
\hline Type of stressor & \multicolumn{2}{|c|}{$\begin{array}{l}\text { SHO/registrar, } n=30 \\
n \quad(\%)\end{array}$} & \multicolumn{2}{|c|}{ Senior registrar, $n=33$} & \multicolumn{2}{|c|}{ Consultants, $n=36$} \\
\hline $\begin{array}{l}\text { Career threat } \\
\text { (e.g. job interview, complaint) }\end{array}$ & 4 & 13.3 & 4 & 12.1 & 6 & 16.6 \\
\hline $\begin{array}{l}\text { Administration } \\
\text { (no beds) }\end{array}$ & 1 & 3.3 & 4 & 12.1 & 9 & 25.0 \\
\hline $\begin{array}{l}\text { Clinical } \\
\text { (on call, use of Mental Health Act, } \\
\text { acting up) }\end{array}$ & 1 & 3.3 & 3 & 9.1 & 2 & 5.5 \\
\hline $\begin{array}{l}\text { Academic } \\
\text { (lack of research, obtaining funding) }\end{array}$ & 0 & 0.0 & 1 & 3.0 & 3 & 8.3 \\
\hline $\begin{array}{l}\text { Patients } \\
\text { (violence, threats, homicide, } \\
\text { suicide) }\end{array}$ & 7 & 23.3 & 4 & 12.1 & 5 & 13.8 \\
\hline Trainee/trainer conflict & 1 & 3.3 & 1 & 3.0 & 1 & 2.7 \\
\hline $\begin{array}{l}\text { Peers } \\
\text { (covering for illness, death } \\
\text { of colleague) }\end{array}$ & 1 & 3.3 & 0 & 0.0 & 5 & 13.8 \\
\hline $\begin{array}{l}\text { Personal } \\
\text { (loss/illness, fertility issues, } \\
\text { relationship problems, personal } \\
\text { illness, family conflict, } \\
\text { moving house) }\end{array}$ & 10 & 33.3 & 5 & 15.2 & 5 & 13.8 \\
\hline
\end{tabular}


Table 3. Ratings of job-related stress: number and percentage of doctors rating work item as moderately or very stressful

\begin{tabular}{|c|c|c|c|c|c|c|c|c|c|}
\hline Stressor & \multicolumn{2}{|c|}{ SHO/registrar, $n=31$} & \multicolumn{2}{|c|}{$\begin{array}{l}\text { Senior registrar, } n=33 \\
n\end{array}$} & Consultants, $n=42$ & $\begin{array}{l}\text { ants, } n=42 \\
(\%)\end{array}$ & $x^{2}$ & d.f. & $P$ \\
\hline Ward rounds & 18 & $(62)$ & 15 & $(45.5)$ & 5 & (13.8) & 16.63 & 2 & $P<0.001$ \\
\hline On-call & 20 & $(68.9)$ & 8 & $(24.2)$ & 5 & (13.8) & 23.79 & 2 & $P<0.00001$ \\
\hline $\begin{array}{l}\text { Unexpected } \\
\text { cover }\end{array}$ & 23 & $(79.3)$ & 14 & $(42.4)$ & 5 & $(13.8)$ & 28.07 & 2 & $P<0.00001$ \\
\hline Violent patients & 24 & $(82.7)$ & 25 & $(75.8)$ & 25 & $(69.4)$ & 1.54 & 2 & $P<0.46$ \\
\hline Angry patients & 25 & $(86.6)$ & 22 & $(66.6)$ & 24 & $(66.6)$ & 3.91 & 2 & $P<142$ \\
\hline $\begin{array}{l}\text { Patients' sexual } \\
\text { problems }\end{array}$ & 23 & $(79.3)$ & 24 & $(72.7)$ & 6 & $(16.6)$ & 32.3 & 2 & $P<0.00001$ \\
\hline $\begin{array}{l}\text { Unable to help } \\
\text { patients }\end{array}$ & 13 & $(44.8)$ & 16 & $(48.5)$ & 17 & $(47.2)$ & 0.08 & 2 & $P=0.96$ \\
\hline $\begin{array}{l}\text { Dealing with } \\
\text { issues to do } \\
\text { with dying }\end{array}$ & 6 & $(20.7)$ & 3 & (9.1) & 9 & (25) & 3.05 & 2 & $P=0.22$ \\
\hline Patients' relatives & 11 & $(37.9)$ & 11 & (33.3) & 13 & $(36.1)$ & 0.14 & 2 & $P=0.92$ \\
\hline $\begin{array}{l}\text { Time off for } \\
\text { sickness }\end{array}$ & 7 & $(24.1)$ & 6 & (18.2) & 17 & $(47.2)$ & 7.64 & 2 & $P<0.05$ \\
\hline Academic work & 21 & $(72.4)$ & 19 & $(57.6)$ & 14 & $(38.8)$ & 7.4 & 2 & $P<0.05$ \\
\hline $\begin{array}{l}\text { Relationships with } \\
\text { junior doctors }\end{array}$ & 3 & $(10.3)$ & 1 & (3) & 2 & $(5.5)$ & 1.46 & 2 & $P=0.47$ \\
\hline $\begin{array}{l}\text { Relations with } \\
\text { nurses }\end{array}$ & 2 & $(6.9)$ & 3 & (9.1) & 11 & $(30.5)$ & 8.48 & 2 & $P<0.05$ \\
\hline Administration & 22 & $(75.8)$ & 20 & $(60.6)$ & 21 & $(58.3)$ & 2.44 & 2 & $P=0.29$ \\
\hline $\begin{array}{l}\text { Relationships } \\
\text { with consultants }\end{array}$ & 7 & $(24.1)$ & 5 & $(15.2)$ & 17 & $(47.2)$ & 9.1 & 2 & $P<0.05$ \\
\hline
\end{tabular}

number and percentage of doctors rating each item as being 'moderately stressful' or 'very stressful' is compared.

Dealing with violent patients was rated as being stressful by more psychiatrists, no matter what grade, than any other item on the stress questionnaire: with $82.7 \%$ of SHOs/registrars, $75.8 \%$ of senior registrars and $69.4 \%$ of consultants rating this item as being moderately or severely stressful. There were marked differences between the grades, however, in the ratings of other items on the stress questionnaire. Ward rounds, on-call, unexpected cover and academic work were all rated as being more stressful by SHOs and registrars compared with consultants, with scores for senior registrars falling inbetween. Consultants rated time off work for sickness, relationships with nurses and relationships with other consultants as being significantly more stressful than either SHOs/ registrars or senior registrars. Interestingly, senior registrars were never the highest scorers on any item of the stress questionnaires, and were either intermediate scorers between SHOs/ registrars and consultants or the lowest scorers.

In an attempt to ascertain which work-related factors might be most closely associated with psychological morbidity in psychiatrists, the group was divided into 'cases' (those scoring above threshold on the GHQ-12) ( $n=27)$ and 'non-cases' those scoring below threshold ( $n=79$ ). There was no difference between cases and noncases on the total scores from the stress questionnaire or on any individual item with exception of covering for colleagues (cases $66 \% v$. non-cases $36 \% \chi^{2} \quad P=0.01$ ) or speaking with relatives (cases $60 \% v$. non-cases $30 \%, P=0.02$ ).

\section{Comment}

The results from this study must be treated with caution due to the small numbers and the reliance upon a self-reort measure. The response rate was reasonable for each grade but lowest for SHOs/registrars. There was no way of determining whether the responders were different from the non-responders because of the importance of maintaining anonymity.

The overall prevalence of psychological distress in psychiatrists was high, with approximately one-quarter scoring above threshold on the GHQ. This figure, however, is very similar to prevalence rates found in other studies of stress and psychological morbidity in doctors in general (Firth-Cozens, 1987; Ramirez et al, 1996). Unlike other studies, we did not find a difference in gender. Female psychiatrists were no more likely to suffer from psychological distress than their male counterparts. 
It is clear that junior psychiatrists reported much higher levels of psychological distress and job-related stress than consultants, and more juniors appeared to experience symptoms of burnout than consultants. This difference could not be explained by the higher proportion of women in the SHO/registrar grade compared with consultant grade, as there was no difference in GHQ scores between males and females. The scores for consultant psychiatrists on the GHQ and Maslach Burnout Inventory are very similar to those obtained by Ramirez et al (1996) for consultants in medicine and surgery, and appear to be representative of doctors working at a senior level.

It is worrying that junior psychiatrists reported more symptoms of burnout than their senior colleagues and in particular felt less able to feel compassionately towards patients than senior colleagues (depersonalisation sub-scale).

It is not possible from the design of this study to identify the causes of such high stress in young psychiatrists, but acute work related stress appeared to be more closely associated with psychological morbidity in SHOs and registrars than the other grades.

The results of this small study suggest that junior psychiatrists face particular stressors in relation to work that are different to those faced by more senior colleagues. Acute on-call work in psychiatry has become more stressful in recent years, particularly in the inner-city areas. Although these stressors affect psychiatrists at all grades juniors are in the front line and face the greatest pressures. It is also possible that consultants report less stress than juniors, as by definition they represent a group of self-selected high achievers, who have chosen psychiatry as a career and have coped with psychiatric training without dropping out.

One of the most striking findings of this study was that many of the spontaneously generated 'stressful factors' on the Stress Incident Record were personal and not related to work. Studies on 'stress-in-the-workplace' often overlook the importance of non-work related stressors. In psychiatry, personal life events (e.g. bereavement) may independently contribute to increased stress, or may make it more difficult for psychiatrists to function at work, particularly if they have to help others who have suffered similar events to themselves. The subtle ways in which job-related factors and personal factors impinge upon one another are difficult to study, but are important to consider.

Factors related to job stress in psychiatrists need to be addressed. This must include better supervision for junior psychiatrists, with recognition from senior doctors of how personal difficulties in a young psychiatrist's life may impinge upon work issues. Pressures upon consultant psychiatrists are unlikely to change unless the providers of mental health services, and in particular consultants who take medical responsibility for the most seriously ill patients, have some influence over the service provision and the number of beds required to safely treat patients. Ramirez et al (1996) have found that autonomy and variety of work are important factors which contribute to consultant job satisfaction, and protect consultants from mental ill health. Further erosion of consultant autonomy in psychiatry is likely to lead to greater job stress.

Dealing with violent patients was the most stressful work-related item for psychiatrists of all grades. This highlights the importance of training in relation to issues of safety but also the importance of the provision of safer working environments for psychiatrists by trusts which employ them.

Although in comparison to other medical specialities, the overall workload of psychiatrists maybe less onerous, the particular nature of the work is very different, and it is sometimes personally threatening. Particular job-related characteristics need to be considered in future work which attempts to compare doctors working in different specialities.

\section{References}

DEARY, I. H., BLENKIN, H., AgIUS, R. M., et al (1996a) Models of job-related stress and personal achievement among consultant doctors. British Journal of Psychology. 87. 3-29.

- AgIUS, R. M. \& SADLER, A. (1996b) Personality and stress in consultant psychiatrists. International Journal of Social Psychiatry, 42, 112-113.

FIRTH-COZENS, J. (1987) Emotional distress in junior house officers. British Medical Journal, 295, 533-536.

GoldBerg. D. \& Williams, P. (1988) A User's Guide to the General Health Questionnaire. Windsor: NFER-Nelson Publishing Co.

KeEnan, A. \& Newton, T. J. (1985) Stressful events, stressors and psychological strains in young professional engineers. Journal of Occupational Behaviour, 6, 151-156.

MASLACH, C. \& JACKSON, S. E. (1981) The Maslach Burnout Inventory. Palo Alto. CA: Consulting Psychologists Press.

NEY, P.G., TAM, W. W. K. \& MAURICE, W. L. (1990) Factors which determine medical student interest in psychiatry. Australian and New Zealand Journal of Psychiatry. 24. 65-76.

Ramirez, A., Graham, J., Richards, M. A., et al (1996) Mental health of hospital consultants: the effects of stress and satisfaction at work. Lancet, 347, 724-28.

Ruch, C. L., \& PrrTs, F. N. (1980) Suicide by psychiatrists: a study of medical specialists among 18730 consecutive physician deaths during a five-year period 1967-72. Journal of Clinical Psychiatry. 41, 261-263.

WALTON, H. J., (1969) Personality correlates of a career interest in psychiatry. British Journal of Psychiatry. 115. $211-219$ 
*Elspeth Guthrie, Senior Lecturer in Psychiatry, University of Manchester, Rawnsley Building. CMHT, Manchester M13 9BX; Teresa Tattan, Research Fellow, University of Manchester, Edwina Williams, Specialist Registrar, Westminster and Chelsea Hospitals, London;
Dawn Black, Consultant Psychiatrist, Hope Hospital, Salford; and Himant Bacliocotti, Specialist Registrar, Nottingham

*Correspondence

\title{
First psychosis liaison unit family education programme
}

\author{
Eric Morris, Catie Harris and Lynley Nolan
}

\begin{abstract}
Aims and methods This study presents an evaluation of an education programme for families whose relative has experienced a first episode of psychosis. Participants attended a five-week programme and were asked to rate their level of knowledge and confidence in managing the illness before and after the education sessions.

Results Two consecutive groups of relatives $(n=9$ : $n=11$ ) attended the programme. Comparison of knowledge and confidence ratings before and after the education sessions demonstrated significant levels of change at the final session for both groups.

Clinical implications Education for relatives of people experiencing psychosis for the first time is an important component in community management. Such education improves the knowledge and confidence of relatives in coping with the illness, possibly leading to a more accepting and less stressful family environment, reducing the risk of relapse and promoting the psychological health of the patient.
\end{abstract}

Assistance in the family management of psychosis can produce significant reductions in relapse rate and produce benefits for the general psychological well-being of the individual with a psychotic illness (Falloon et al, 1982). A reduction in subsequent relapses after a first episode of illness may help prevent chronicity and associated disability (Jackson \& Birchwood, 1996).

An important component of the family management process is education of the family regarding the illness, the role of various treatment providers, problem-solving and managing crises, and the variety of services available to the family and the individual (Tarrier \& Barrowclough et al, 1987).
We describe a family education programme which is part of the first psychosis service (First Psychosis Liaison Unit; FPLU) based at the Mills Street Centre, Perth. Western Australia. The Mills Street Centre services a socio-economically diverse catchment area of around 120000 adults. The FPLU, a community-based initiative, became operational in late August 1995 and aims to facilitate the provision of personalised comprehensive care for young people (aged 16 to 35 years) experiencing a first episode of psychosis. This is achieved by fostering effective links between relevant health, welfare, employment and education-related agencies. FPLU provides case management for individuals in the first episode of a psychotic illness and operates as an adjunct to the existing multi-disciplinary mental health service. Case management is conducted by clinical liaison officers, who are trained mental health professionals from either social work, community mental health nursing or occupational therapy backgrounds working in generic positions. Other components of the FPLU service include individual and family support, community education, promotion of early identification of psychosis and clinical research.

The FPLU Family Education Programme aims to provide family members with accurate information and to encourage the use of this information to enhance familial adjustment to having a member with a psychotic illness. It is expected that this will enable more appropriate use of services, better communication between family members and treatment providers, and improve the coping skills of the family. In addition the programme allows the participants to meet other families who are facing the same 